\title{
The longitudinal variability of equatorial electrojet and vertical drift velocity in the African and American sectors
}

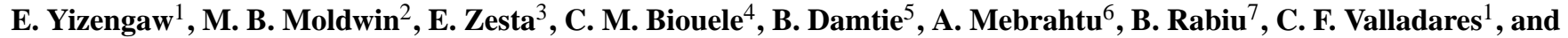 \\ R. Stoneback ${ }^{8}$ \\ ${ }^{1}$ Institute for Scientific Research, Boston College, Boston, Massachusetts, USA \\ ${ }^{2}$ Department of Atmospheric, Oceanic and Space Sciences, University of Michigan, Ann Arbor, Michigan, USA \\ ${ }^{3}$ NASA Goddard Space Flight Center, Greenbelt, Maryland, USA \\ ${ }^{4}$ Department of Physics, University of Yaoundé I, Yaoundé, Cameroon \\ ${ }^{5}$ Washera Geospace and Radar Science Laboratory, Bahir Dar University, Bahir Dar, Ethiopia \\ ${ }^{6}$ Department of Physics, Adigrat University, Adigrat, Ethiopia \\ ${ }^{7}$ National Space Research and Development Agency, Abuja, Nigeria \\ ${ }^{8}$ Center for Space Sciences, University of Texas at Dallas, Richardson, Texas, USA
}

Correspondence to: E. Yizengaw (kassie@bc.edu)

Received: 15 November 2013 - Revised: 23 January 2014 - Accepted: 30 January 2014 - Published: 13 March 2014

\begin{abstract}
While the formation of equatorial electrojet (EEJ) and its temporal variation is believed to be fairly well understood, the longitudinal variability at all local times is still unknown. This paper presents a case and statistical study of the longitudinal variability of dayside EEJ for all local times using ground-based observations. We found EEJ is stronger in the west American sector and decreases from west to east longitudinal sectors. We also confirm the presence of significant longitudinal difference in the dusk sector pre-reversal drift, using the ion velocity meter (IVM) instrument onboard the C/NOFS satellite, with stronger pre-reversal drift in the west American sector compared to the African sector. Previous satellite observations have shown that the African sector is home to stronger and year-round ionospheric bubbles/irregularities compared to the American and Asian sectors. This study's results raises the question if the vertical drift, which is believed to be the main cause for the enhancement of Rayleigh-Taylor (RT) instability growth rate, is stronger in the American sector and weaker in the African sector - why are the occurrence and amplitude of equatorial irregularities stronger in the African sector?
\end{abstract}

Keywords. Ionosphere (electric fields and currents; equatorial ionosphere; ionospheric irregularities)

\section{Introduction}

The worldwide solar-driven wind results in the so-called Sq (solar quiet) current system in the E region of the earth's ionosphere (100-130 km altitude). The Sq current in turn causes the generation of an east-west electrostatic field at the equatorial ionosphere, which is directed eastward during dayside. At the magnetic dip equator, where the geomagnetic field is horizontal, this electric field results in an enhanced eastward current flow along the magnetic equator, known as the equatorial electrojet (EEJ) (e.g., Stening, 1995). The $\mathrm{EEJ}$ is a narrow (within $\pm 3^{\circ}$ of the magnetic equator) ribbon of current flowing eastward in the daytime equatorial region of the earth's ionosphere. Since its discovery, after the installation of a geomagnetic observatory at Huancayo (Peru) near the dip equator, the EEJ has been the subject of many studies. Most of the first studies were carried out to explain the generating mechanism of such an intense current flow along the dip equator (Baker and Martyn, 1953; Chapman and Bartels, 1940). Since the 1970s, some theories and physical models of the ionospheric dynamo have been developed (e.g., Richmond, 1973; Stening, 1995) in order to explain the mechanism of the EEJ flow and its main features, such as day-to-day and seasonal variability, counter-electrojet, electrodynamics processes of coupling with global-scale current systems, etc. 
The longitudinal variability of the EEJ has not been thoroughly investigated due to the lack of ground-based instrument observations that track the temporal variation of the electrojet at different longitudes. Thus, the study of the longitudinal variability of the EEJ has been possible only using in situ rocket (e.g., Onwumechili, 1997) or LEO satellite (e.g., Ivers et al., 2003; England et al., 2006; Luhr et al., 2008) observations. The first global longitudinal picture of the EEJ was deduced from the polar orbiting geophysical observatory (POGO) satellite observations (e.g., Onwumechili and Agu, 1981). Then the launch of different LEO satellites with magnetometers onboard, such as Ørsted, Challenging Minisatellite Payload (CHAMP), and Scientific Application Satellite$\mathrm{C}$ (SAC-C), provide the opportunity to image the longitudinal EEJ distribution which shows some common features. Both Ørsted (e.g., Ivers et al., 2003) and CHAMP (e.g., Luhr et al., 2004) observations show clear dependence on longitude, with stronger EEJ intensity peaks over South America and Indonesia, which they attributed to the dependence of the Cowling conductivity on the ambient field strength. Similarly, England et al. (2006) reported a four-peaked longitudinal structure of noontime EEJ during equinox seasons, and it was attributed to a large-scale variation of the $\mathrm{E}$ layer dynamo driven by tidal winds, which is caused by nonmigrating tides originating in the tropical troposphere (e.g., Forbes et al., 2006).

It has been well accepted that the vertical $\boldsymbol{E} \times \boldsymbol{B}$ drift velocity in the equatorial $\mathrm{F}$ region can be estimated using pairs (one placed at the geomagnetic equator and one off the equator) of ground-based magnetometer observations (Anderson et al., 2002, 2004; Yizengaw et al., 2011, 2012). The $H$ component observations from a magnetometer located $6^{\circ}$ to $9^{\circ}$ away from the magnetic equator are then subtracted from the $H$ component value measured by a magnetometer on the magnetic equator, and this eliminates the Dst ring current and the global Sq dynamo components of $H$. The resulting difference is thus only related to the ionospheric electrojet current and hence the east-west electrostatic field of ionospheric origin not associated with the ring or the Tail currents (Anderson et al., 2004). The electric field or EEJ varies with longitude, season, local time, and on a day-to-day basis.

The situation of the ground-based instruments improved considerably after the launch of a United Nations sponsored program known as the International Space Weather Initiative (ISWI), a continuation of the International Heliophysical Year (IHY), which has facilitated the deployment of a number of small instrument arrays, including magnetometers (Yizengaw et al., 2013a). These arrays of instruments allow us to partially cover the largest landmass beneath the geomagnetic equator, especially in regions that had been devoid of ground-based instruments, such as in Africa.

In this study, data from five pairs of magnetometers that are distributed in the South American and African sectors are used to examine the temporal longitudinal variability of EEJ and thus the vertical drift. Similarly, data from an ion velocity meter (IVM) instrument onboard the Communications/Navigation Outage Forecasting System (C/NOFS) satellite have also been used to perform the longitudinal variation of in situ drift velocity.

\section{Data analysis}

Through a cooperative program with the United Nations Basic Space Science (UNBSS) program, the IHY/ISWI has facilitated the deployment of a number of arrays of small instruments to make global measurements of space-physicsrelated phenomena. The African Meridian $B$ field Education and Research (AMBER) magnetometer array is one of the ground-based instruments deployed in Africa under the IHY program (Yizengaw and Moldwin, 2009). The AMBER array contains fifteen magnetometers (either deployed or in the process of deployment) and spans across Africa, Asia and Brazil beneath the geomagnetic equator from the $\mathrm{L}$ of 1.0 to an $\mathrm{L}$ of 1.4. One of the objectives of the AMBER array is to address the processes that govern the electrodynamics of the equatorial ionosphere in the African sector and compare and contrast with electrodynamics in other longitudinal sectors. Similarly, the Low Latitude Ionospheric Sensor Network (LISN) project (Valladares and Chau, 2012) has been instrumental in deploying five magnetometers in the Peruvian and west Brazilian sector along the geomagnetic equator.

The magnitude and direction of the dayside vertical velocity $(\boldsymbol{E} \times \boldsymbol{B}$ drift) can be easily estimated using pairs of ground magnetometers around the dip equator (Anderson et al., 2004, 2006; Yizengaw et al., 2011, 2012). The equatorial electrojet current (EEJ) produces a strong enhancement in the $\mathrm{H}$ component magnetic field measured by magnetometers located within $\pm 3^{\circ}$ of the magnetic equator. In principle, measuring this perturbation in equatorial magnetometers could provide a direct measure of the EEJ. However, ground magnetometers respond to all currents within their field of view. Equatorial stations respond primarily to the EEJ, which is directly overhead, but also to the ring current and the global quiet time Sq current system. The typical extent of the EEJ is within $\pm 3^{\circ}$ of the dip equator. Ground magnetometers just outside the extent of the EEJ, $6^{\circ}-9^{\circ}$ off the dip equator, would exhibit near-zero response to the EEJ, but have the same response to the ring and $\mathrm{Sq}$ currents as an equatorial station. The ring current and global Sq dynamo contribution to the $H$ component can then be removed by taking the difference between the $H$ component recorded at the magnetic equator and off the equator $\left(\sim 6-9^{\circ}\right.$ geomagnetic). The difference is the only part of the $H$ component field that is related to the EEJ current contribution which, in turn, is directly related to the east-west electric field. Therefore, the $\boldsymbol{E} \times \boldsymbol{B}$ drift can be estimated using the resulting difference $(\Delta H)$ value of the $\mathrm{H}$ component field (see Anderson et al., 2004). To avoid different offset values of different magnetometers, 


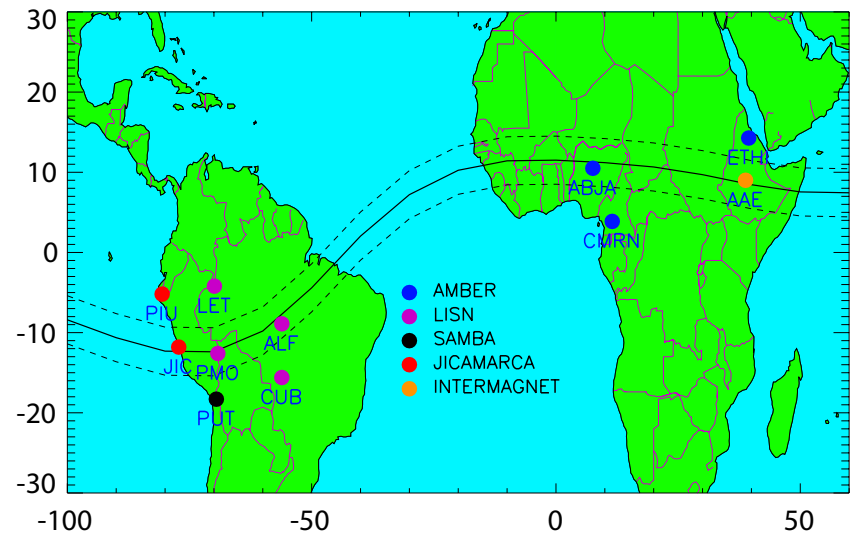

Fig. 1. Geographic location of the ground-based magnetometers used for this study. The solid horizontal line depicts the geomagnetic equator, and the two dashed lines indicate the EEJ region.

the nighttime baseline values in the $H$ component are first obtained for each day and subtracted from the corresponding magnetometer data sets. This provides the variation of daytime $H$ component values of each magnetometer.

For this study the list of magnetometers that have been used for EEJ observation and thus estimation of drifts at different longitudes are given in Table 1. The geographic locations of these magnetometers are shown in Fig. 1. We also inspect data from IVM instrument onboard the Communication/Navigation Outage Forecasting System (C/NOFS) satellite to see the longitudinal variability of the in situ drift observations. Unlike the magnetometer observations, the IVM data provides in situ drift values for both day and night local time sectors. We selected IVM data only when C/NOFS orbits within $\pm 8^{\circ}$ of the dip equator and altitude below $500 \mathrm{~km}$. The IVM data are also arranged within $\pm 3.5^{\circ}$ of the longitudes where we have magnetometer observations.

\section{Observations}

Figure 2 shows a typical example of EEJ and equatorial drifts estimated from magnetometer pairs located in the west American sectors on 2 January 2010. The top plots show the $H$ component field variation recorded at the geomagnetic equator (red curve) and off the equator (green curve). The black curve is the difference between the red and green curves $(\Delta H)$, representing the isolated effect of the equatorial electrojet current. The blue curve in the bottom plot is the $\boldsymbol{E} \times \boldsymbol{B}$ drift estimated from the corresponding $\Delta H$ values (black curve in the top plot), using the technique described in Anderson et al. (2004). The drift velocity, estimated from magnetometer observations, has also been validated with radar (red dots) measurements, showing excellent agreement between the two independent observations.

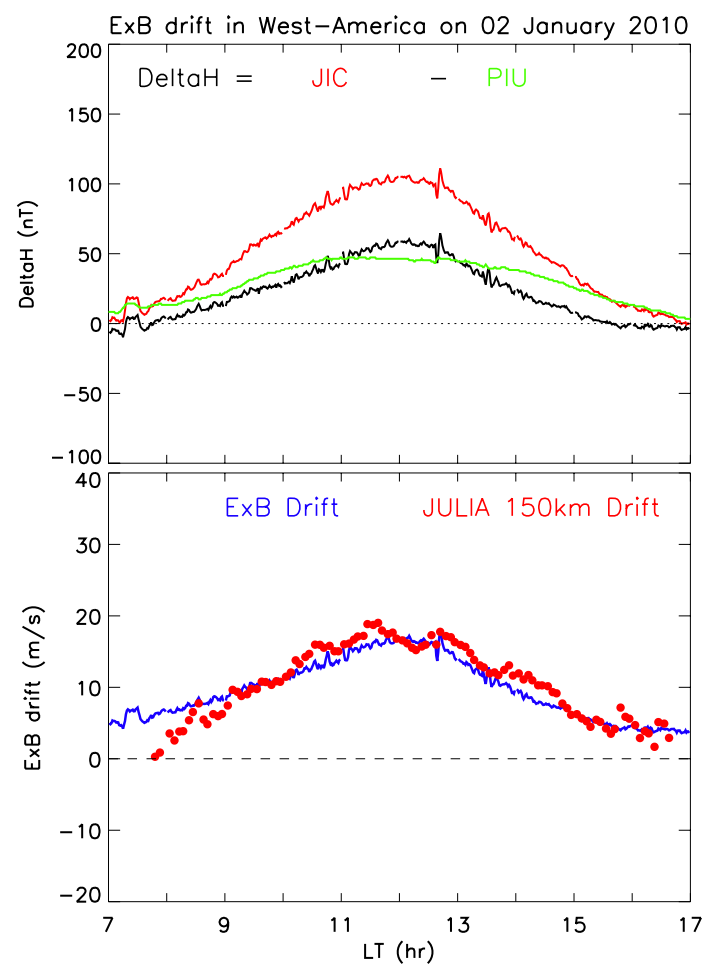

Fig. 2. (Top panels) the magnetic fluctuation recorded at the geomagnetic equator (red curves) and off the magnetic equator (green curves) and the difference between red and green curve (black curve). (Bottom panels) an estimated $\boldsymbol{E} \times \boldsymbol{B}$ drift (blue curve) and red dots represent vertical drift velocity observed by the JULIA $150 \mathrm{~km}$ radar, respectively.

The isolated effect of the equatorial electrojet current (the black curve in top panel of Fig. 2) and the corresponding drift velocities have been estimated using pairs of magnetometers located at different longitudes and compared to each other to investigate the longitudinal variability of EEJ. Figure 3 shows the EEJ currents (top panel) and the corresponding drift velocities (bottom panel). The different color of the curves represents different longitudes which are shown in Table 1. It shows the EEJ and thus vertical drift decreases in magnitude from the American to African sectors. The EEJ and drift at Jicamarca is greater than the one in Addis Ababa by about $40 \%$. These longitudinal drift trends have been observed for most of the events. Figure 4 shows 4-year (20102013) average statistical plots of EEJ (left panels) and the corresponding vertical drift velocity (right panels), which are plotted in local time versus months of the year. Each panel represents different longitudes, which are given at the right side of each panel. The white areas indicate data were not available from either of the pair stations in that longitudinal sector. Data from both the equator and off the equator stations are required to obtain the EEJ and $\boldsymbol{E} \times \boldsymbol{B}$ drift. In general, the longitudinal EEJ and $\boldsymbol{E} \times \boldsymbol{B}$ drift distribution have higher values in the west American sector and start decreasing to the 
Table 1. List of magnetometer stations used.

\begin{tabular}{lllrrrr}
\hline Station name & Station code & Project it belongs to & Geog. Lat. & Geog. Lon. & Geom. Lat. & Geom. Lon. \\
\hline Adigrat & ETHI & AMBER & $14.3^{\circ} \mathrm{N}$ & $39.5^{\circ} \mathrm{E}$ & $6.0^{\circ} \mathrm{N}$ & $111.1^{\circ} \mathrm{E}$ \\
Abuja & ABJA & AMBER & $10.5^{\circ} \mathrm{N}$ & $7.55^{\circ} \mathrm{E}$ & $0.6^{\circ} \mathrm{S}$ & $79.6^{\circ} \mathrm{E}$ \\
Yaounde & CMRN & AMBER & $3.9^{\circ} \mathrm{N}$ & $11.5^{\circ} \mathrm{E}$ & $5.8^{\circ} \mathrm{S}$ & $83.1^{\circ} \mathrm{E}$ \\
Addis Ababa & AAE & INTERMAGNET & $9.0^{\circ} \mathrm{N}$ & $38.8^{\circ} \mathrm{E}$ & $0.9^{\circ} \mathrm{N}$ & $110.5^{\circ} \mathrm{E}$ \\
Jicamarca & JIC & JRO & $11.8^{\circ} \mathrm{S}$ & $77.2^{\circ} \mathrm{W}$ & $0.8^{\circ} \mathrm{N}$ & $5.7^{\circ} \mathrm{W}$ \\
Piura & PIU & JRO & $5.2^{\circ} \mathrm{S}$ & $80.6^{\circ} \mathrm{W}$ & $6.8^{\circ} \mathrm{N}$ & $9.4^{\circ} \mathrm{W}$ \\
Puerto Maldonado & PMO & LISN & $12.6^{\circ} \mathrm{S}$ & $69.2^{\circ} \mathrm{W}$ & $0.1^{\circ} \mathrm{N}$ & $2.1^{\circ} \mathrm{E}$ \\
Leticia & LET & LISN & $4.2^{\circ} \mathrm{S}$ & $69.9^{\circ} \mathrm{W}$ & $8.0^{\circ} \mathrm{N}$ & $2.0^{\circ} \mathrm{E}$ \\
Cuiaba & CUB & LISN & $15.6^{\circ} \mathrm{S}$ & $56.1^{\circ} \mathrm{W}$ & $5.9^{\circ} \mathrm{S}$ & $13.8^{\circ} \mathrm{E}$ \\
Alta Floresta & ALF & LISN & $9.9^{\circ} \mathrm{S}$ & $56.1^{\circ} \mathrm{W}$ & $0.8^{\circ} \mathrm{S}$ & $15.2^{\circ} \mathrm{E}$ \\
Putre & PUT & SAMBA & $18.3^{\circ} \mathrm{S}$ & $69.5^{\circ} \mathrm{W}$ & $5.5^{\circ} \mathrm{S}$ & $1.4^{\circ} \mathrm{E}$ \\
\hline
\end{tabular}

east, with the exception of EEJ and $\boldsymbol{E} \times \boldsymbol{B}$ drift magnitudes in the West African sector, which is a bit lower than the EEJ in the East African sector. One of the station pairs in the West African sector was deployed in August 2011 and had a power interruption problem and thus data coverage was not as good as is shown in the plot, with data unavailability for extended time periods. In addition to the longitudinal variability, the EEJ and $\boldsymbol{E} \times \boldsymbol{B}$ drift shows clear seasonal differences in magnitude, with higher magnitudes during equinoxes and lower magnitudes in the June solstice.

Figure 5 shows the longitudinal and seasonal variability of drift velocity measured by the IVM instrument onboard the C/NOFS satellite. The IVM data are from the period of January 2009 to May 2013. For the purpose of this study, the IVM drift data that are available within $\pm 3.5^{\circ}$ of each longitude shown at the top of Fig. 5 are filtered and binned into $15 \mathrm{~min}$ time averages for each longitudinal sector. The longitudinal sectors shown at the top for the corresponding colors are the same as the meridians where we have the groundbased magnetometer pairs. Furthermore, the IVM data that were recorded in the region when the satellite was traversing above $500 \mathrm{~km}$ altitude and outside $\pm 8^{\circ}$ geomagnetic latitudes have not been used for this study. In general, the IVM drift velocity also shows stronger drift velocity in magnitude in the American sector compared to the African sector during almost all local time sectors. The pre-reversal drift velocities, which are not possible to estimate using ground-based magnetometers due to weak EEJ during the dusk and night periods, are also stronger in the west American sector compared to the African sector, as shown in all seasons except during the June solstice. During June solstice the pre-reversal drift velocity is weak or even non-existent in the African and east American sectors, as shown in the top right panel of Fig. 5.

\section{Discussion and conclusions}

In this study we used pairs of magnetometers located at different longitudes and investigated the longitudinal/seasonal

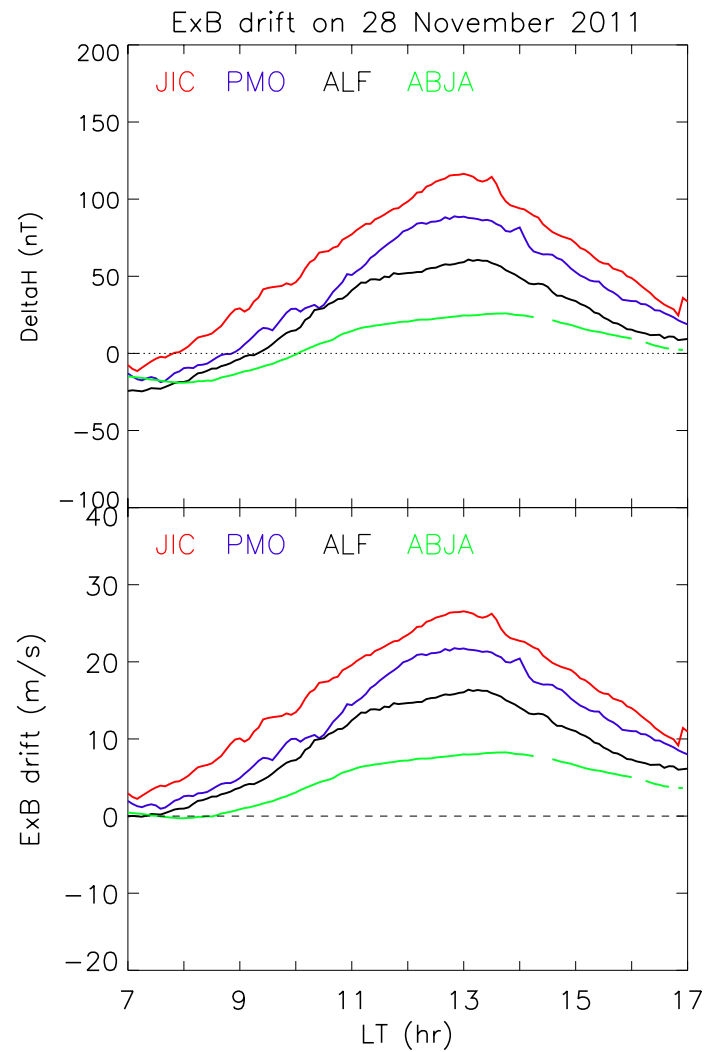

Fig. 3. The difference between magnetic fluctuation recorded at the geomagnetic equator and off the equator (top panels), and an estimated $\boldsymbol{E} \times \boldsymbol{B}$ drift (bottom panel). Different colors both in the bottom and top panels represent different longitudinal sectors.

variability of the EEJ intensity and the vertical $\boldsymbol{E} \times \boldsymbol{B}$ drift magnitude and direction. The recently expanded coverage of ground-based instruments provides an excellent opportunity, for the first time, to investigate the longitudinal variability of the drift and EEJ from the ground. The advantage of the ground-based observations is that they allow monitoring of not only longitudinal but also temporal variations of the EEJ 

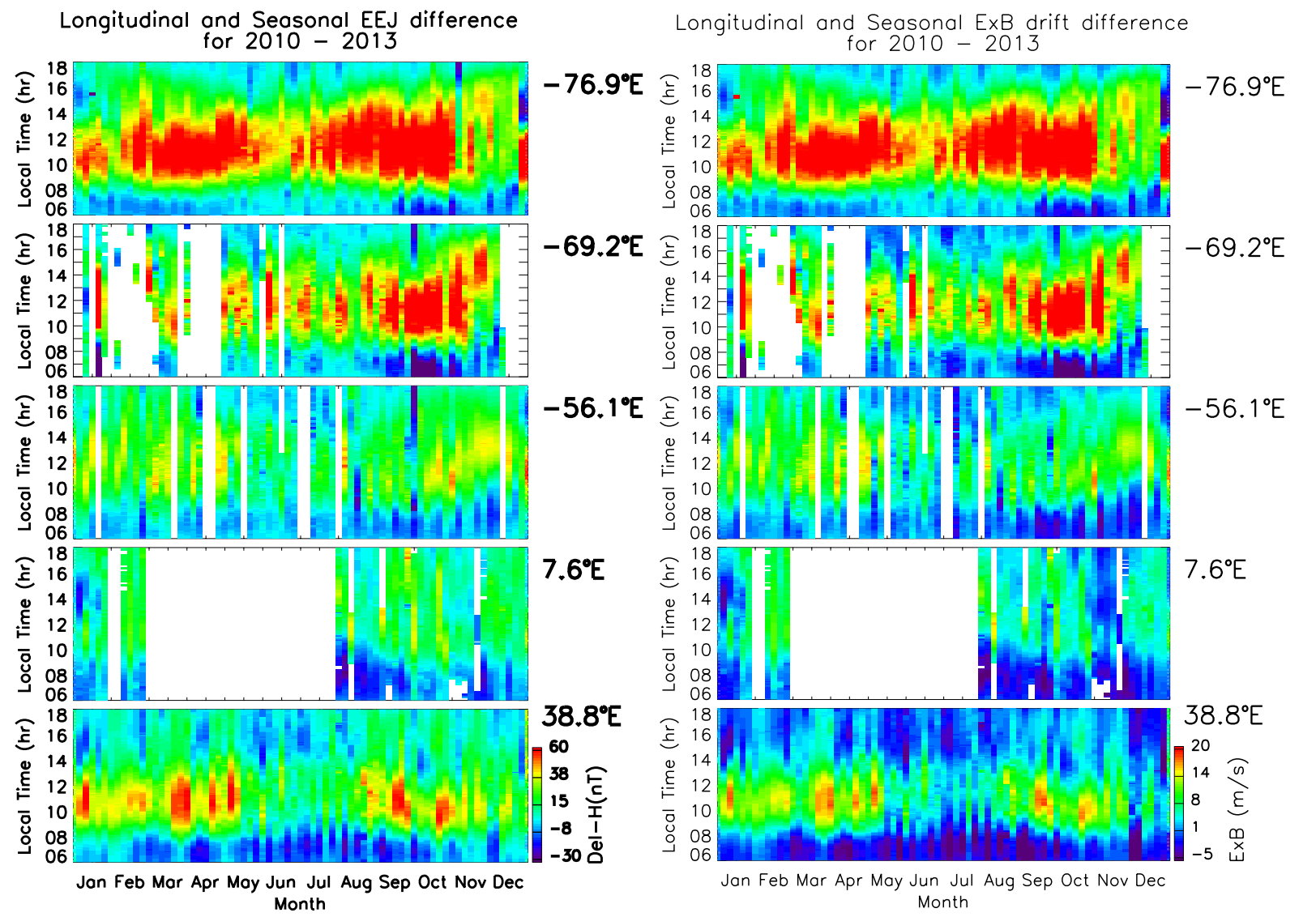

$-69.2^{\circ} \mathrm{E}$
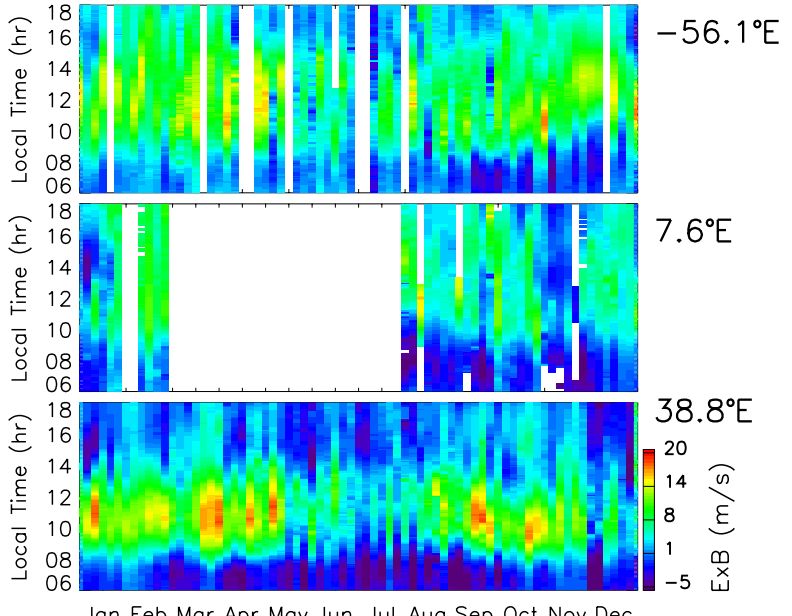

Jan Feb Mar Apr May Jun Jul Aug Sep Oct Nov Dec

$7.6^{\circ} \mathrm{E}$ Month

Fig. 4. (Left panel) shows 4-year (2010-2013) average statistical local time as a function of day of the year plots of EEJ, and (left panels) indicates the corresponding vertical drift velocity. From top to bottom, different panels represent different longitudinal sectors which are given at the right side of each panel.

and drift at different longitudes, in which magnetometers onboard the LEO satellite, like CHAMP, are not able to monitor due to the limited local time coverage at fixed longitudes. Another important benefit of the continuous ground-based observations is that they provide a comprehensive overview of not only the longitudinal but also diurnal and temporal variability of the EEJ and $\boldsymbol{E} \times \boldsymbol{B}$ drift distribution as shown in Fig. 4. Although the magnitudes are different, EEJ and vertical drifts in all longitudinal sectors show consistent seasonal variation with peaks during equinox and weaker during June solstice which is consistent with earlier observations (e.g., Fejer and Scherliess, 2001). Both the magnetometer measurements (see Figs. 3-4) and IVM observation (see Fig. 5) show stronger EEJ strength and $\boldsymbol{E} \times \boldsymbol{B}$ drift in the west American and weaker in the East African longitudinal sectors, with the exception that the magnetometer data are weaker in the West African sector (this could be due to lack of continuous data coverage in the West African sector mentioned in Sect. 3). The general longitudinal distribution trend is consistent with earlier satellite observations (e.g., Luhr et al., 2004) and model estimation (e.g., Doumouya et al., 2003). Luhr et al. (2004), using magnetometer data onboard the
CHAMP satellite, reported a detailed picture of the longitudinal variability of EEJ, but only for noon local time, and found stronger EEJ strength in the west American (around $60^{\circ} \mathrm{W}$ ) and Indonesian (around $100^{\circ} \mathrm{E}$ ) sectors and an absolute minimum in the East African (around $40^{\circ} \mathrm{E}$ ) region. Similarly, Doumouya et al. (2003), using an empirical model of EEJ, which was constructed based on the magnetometer data from 26 stations located at six different longitudes, reported stronger and weaker EEJ in South America (with a maximum between $80^{\circ}$ and $100^{\circ} \mathrm{W}$ ) and in India (between $75^{\circ}$ and $100^{\circ} \mathrm{E}$ ), respectively.

Our two independent observations, as well as earlier modeling and satellite measurements of EEJ (e.g., Doumouya et al., 2003; Luhr et al., 2004), consistently show weaker dayside vertical drift or EEJ in the African sector compared with the American sector. The dusk sector vertical drift (see Fig. 5), observed by IVM instrument onboard the C/NOFS, also shows a similar trend, i.e., weaker in the African than American sectors. In contrast to these results, ionospheric irregularities, which are associated to the magnitude and direction of vertical $\boldsymbol{E} \times \boldsymbol{B}$ drifts and thus the enhancement of Rayleigh-Taylor instability (RTI) growth rates, that 


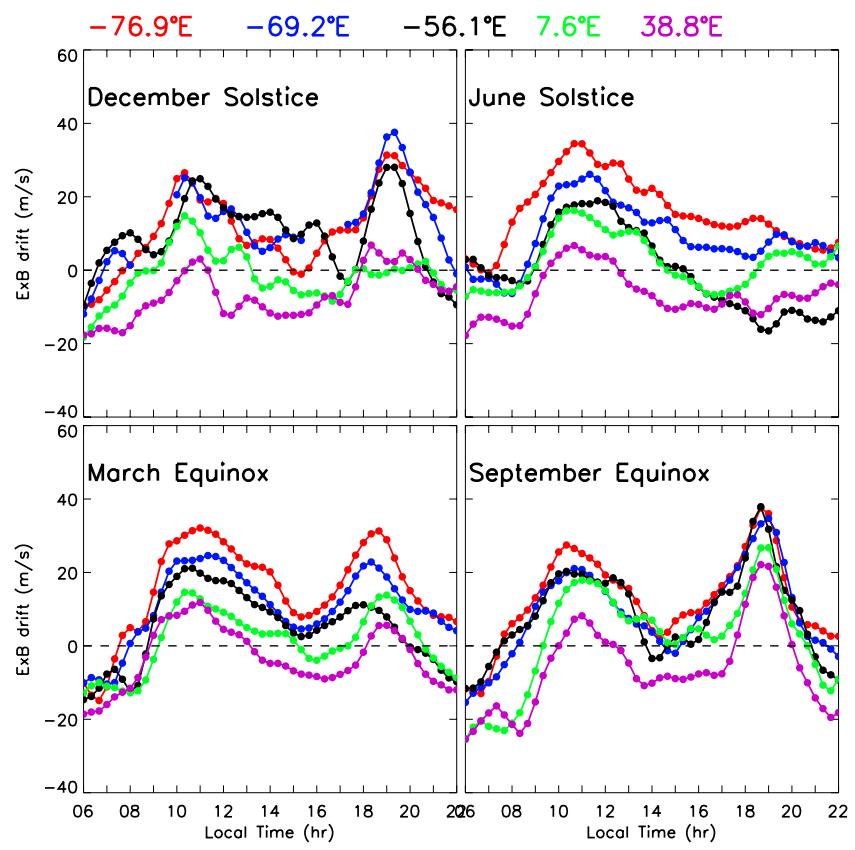

Fig. 5. Shows statistical temporal, longitudinal, and seasonal variability of drift velocity measured by the IVM instrument onboard the C/NOFS satellite. Different colors represent different longitudinal sectors, which are given at the top.

normally start right after sunset local time, are stronger and active all year in the African sector, even during June solstice (e.g., Hei et al., 2005). Figure 6 shows a typical example of a 3-year (2009-2011) average distribution of bubbles/irregularities, estimated from a global positioning system (GPS) total electron content (TEC) data using the technique described in Seemala and Valladares (2011), for different longitudes given at the right side of each panel. The figure clearly shows activity in all seasons and strong bubbles/irregularities in the African sector compared to other longitudinal sectors. Recently, Yizengaw et al. (2013b) reported significantly strong bubbles in the African sector during post-midnight local time under magnetically quiet conditions in June solstice. The question is if the drift is weaker in the African sector, what causes these strong bubbles that have been observed in the African sector almost throughout the night and during all seasons? Are there other mechanisms that initiate RTI growth rate other than vertical drift? According to the RTI growth rate formula, which is given by $\gamma=\frac{\Sigma_{\mathrm{F}}}{\Sigma_{\mathrm{F}}+\Sigma_{\mathrm{E}}}\left(V_{\mathrm{dr}}-U_{\perp}-\frac{g}{V_{\text {eff }}}\right) \frac{1}{N_{\mathrm{e}}} \frac{\mathrm{d} N_{\mathrm{E}}}{\mathrm{d} h}$, the vertical drift is supposed to be the primary component to enhance the RTI growth rate (Sultan, 1996). (The $\Sigma_{\mathrm{F}}$ and $\Sigma_{\mathrm{E}}$ are $\mathrm{F}$ and $\mathrm{E}$ region Pederson conductivities, respectively); $V_{\mathrm{dr}}, U_{\perp}, g, \nu_{\mathrm{eff}}, N_{\mathrm{E}}$ represent, vertical drift, perpendicular neutral wind component, gravity, collision frequency, and electron density, respectively. However, in the African sector that does not seem to be the case. If not the drift, then what could it be? Would it be the neutral winds that cause the

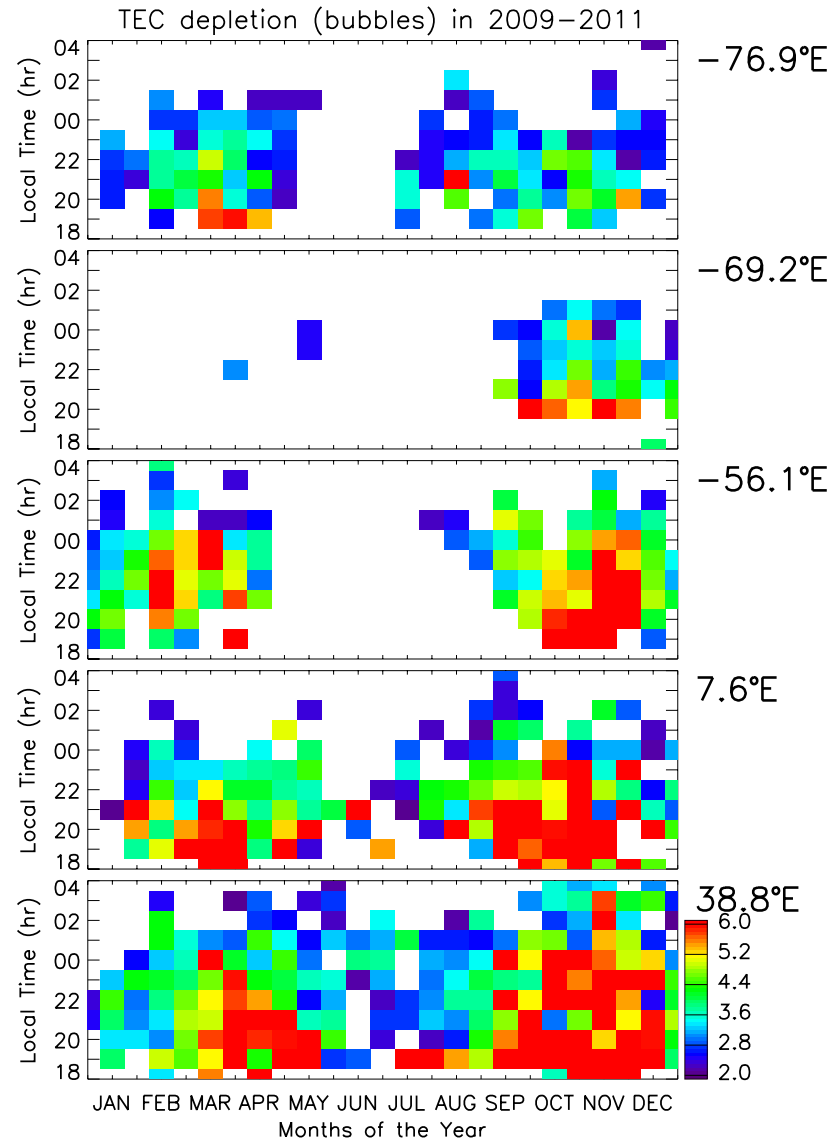

Fig. 6. The distribution of bubbles/irregularities, estimated from GPS TEC recorded from 2009 to 2011, as a function local time versus months. The different panels represent different longitudinal sectors, which are given at the right side of each panel. The color index represents the TEC depth (the TEC difference between tough and crust region of the bubble).

long-lasting bubbles in Africa? If it is the neutral wind, why are the winds unique in terms of orientation and magnitude in the African sector compared to other longitudinal sectors? Addressing all these questions is beyond the scope of this paper, because at the very least it requires continuous measurement of the wind in a region that has never been studied before. Recently, Huba and Krall (2013) demonstrated using their SAMI3/ESF model that the meridional wind may account for the longitudinal and day-to-day variability of the bubbles/irregularities. However, the neutral wind estimation in the African sector, a region that has been devoid of ground-based neutral wind measuring instruments, such as Fabry-Perot Interferometer (FPI) instrument, has been based on only model output. The three funded FPI instruments that are in preparation to be deployed in Morocco and Ethiopia will be instrumental to solving the mystery of the neutral wind orientation and magnitude and understanding the mechanism of how the neutral winds can be a primary driver of the bubbles/irregularities in the African sector, which are described in detail above. 
In conclusion, this study examined the longitudinal and temporal variability of the EEJ and $\boldsymbol{E} \times \boldsymbol{B}$ drift. We characterized the dayside temporal and longitudinal variations of the EEJ and $\boldsymbol{E} \times \boldsymbol{B}$ drift velocity, showing clear and consistent differences as a function of longitude. We also demonstrated the existence of similar longitudinal differences in dusk sector vertical drift velocity. In general, the following points can be taken as the main results of this study.

- Four years (2010-2013) of extensive ground-based observations show consistently stronger dayside EEJ and vertical drift in the west American sector that decreases to eastern longitudes all the way to the East African sector.

- In addition to the dayside drift velocities, the five years of C/NOFS satellite (2009-2013) dusk sector vertical drifts (pre-reversal drifts) show similar longitudinal variability - stronger in the American than African sector.

- Our results are in contrast to the longitudinal distribution of bubbles/irregularities found in earlier studies, where irregularities were stronger and active all year in the African longitudes compared to the American sector. This suggests that other mechanisms, in addition to vertical drift, contribute to equatorial ionospheric irregularities in the African sector and suggest that future investigations are needed to understand the cause of these longitudinal differences.

Acknowledgements. This work was supported by NASA LWS (NNX10AQ53G and NNX11AP02G) and AFOSR (FA9550-12-10437) grants. The authors are indebted to the Jicamarca radio observatory (JRO) and INTERMAGNET team for the magnetometer data resources they made available to the public.

Topical Editor J. Klenzing thanks J. Huba and one anonymous referee for their help in evaluating this paper.

\section{References}

Anderson, D., Anghel, A., Yumoto, K., Ishitsuka, M., and Kudeki, E.: Estimating daytime vertical ExB drift velocities in the equatorial F-region using ground-based magnetometer observations, Geophys. Res. Lett., 29, 1596, doi:10.1029/2001GL014562, 2002.

Anderson, D., Anghel, A., Chau, J. L., and Yumoto, K.: Global, low-latitude, vertical ExB drift velocities inferred from daytime magnetometer observations, Space Weather, 4, S08003, doi:10.1029/2005SW000193, 2006.

Anderson, D., Anghel, A., Chau, J., and Veliz, O.: Daytime vertical $\mathrm{E} \times \mathrm{B}$ drift velocities inferred from ground-based magnetometer observations at low latitudes, Space Weather, 2, S11001, doi:10.1029/2004SW000095, 2004.
Baker, W. G. and Martyn, D. F.: Electric current in the ionosphere, The conductivity, Phil. Trans. Roy. Soc London A, 245, 251-294, 1953.

Chapman, S. and Bartels, J.: Geomagnetism, Clarendon Press, Oxford, 1940.

Doumouya, V., Cohen, Y., Arora, B. R., and Yumoto, K.: Local time and longitude dependence of the equatorial electrojet magnetic effects, J. Atmos. Solar-Terr. Phys., 65, 1256-1282, 2003.

England, S. L., Maus, S., Immel, T. L., and Mende, S. B.: Longitude variation of the E-region electric fields caused by atmospheric tides, Geophys. Res. Lett., 33, L21105, doi:10.1029/2006GL027465, 2006.

Fejer, B. G. and Scherliess, L.: On the variability of equatorial Fregion vertical plasma drifts, J. Atmos. Solar-Terr. Phys., 63, 893-897, 2001.

Forbes, J. M., Russell, J., Miyahara, S., Zhang, X., Palo, S., Mlynczak, M., C., Mertens, J., and Hagan, M. E.: Tropospherethermosphere tidal coupling as measured by the SABER instrument on TIMED during July-September 2002, J. Geophys. Res., 111, A10S06, doi:10.1029/2005JA011492, 2006.

Hei, M. A., Heelis, R. A., and McClure, J. P.: Seasonal and longitudinal variation of large-scale topside equatorial plasma depletions, J. Geophys. Res., 110, A12315, doi:10.1029/2005JA011153, 2005.

Huba, J. D. and Krall, J.: Impact of meridional winds on equatorial spread F: Revisited, Geophys. Res. Lett., 40, 1268-1272, doi:10.1002/grl.50292, 2013.

Ivers, D., Stening, R., Turner, J., and Winch, D.: Equatorial electrojet from Ørsted scalar magnetic field observations, J. Geophys. Res., 108, 1061, doi:10.1029/2002JA009310, 2003.

Luhr, H., Maus, S., and Rother, M.: The noon-time equatorial electrojet, its spatial features as determined by the CHAMP satellite, J. Geophys. Res., 109, A01306, doi:10.1029/2002JA009656, 2004.

Luhr, H., Rother, M., Häusler, K., Alken, P., and Maus, S.: The influence of non-migrating tides on the longitudinal variation of the equatorial electrojet, J. Geophys. Res., 113, A08313, doi:10.1029/2008JA013064, 2008.

Onwumechili, C. A.: The Equatorial Electrojet, Gordon and Breach, 1997.

Onwumechili, C. A. and Agu, C. E.: Longitudinal variation of equatorial electrojet parameters derived from POGO satellite observations, Planet. Space Sci., 29, 627-634, 1981.

Richmond, A. D.: Equatorial electrojet-1. Development of a model including winds and instabilities, J. Atmos. Terr. Phys., 35, 1083-1103, 1973.

Seemala, G. K. and Valladares, C. E.: Statistics of total electron content depletions observed over the South American continent for the year 2008, Radio Sci., 46, RS5019, doi:10.1029/2011RS004722, 2011.

Stening, R. J.: What drives the equatorial electrojet?, J. Atmos. Terr. Phys., 57, 1117-1128, 1995.

Sultan, P. J.: Linear theory and modeling of the Rayleigh-Taylor instability leading to the occurrence of equatorial spread F, J. Geophys. Res., 101, 26875-26891, doi:10.1029/96JA00682, 1996.

Valladares, C. E. and Chau, J. L.: The Low-Latitude Ionosphere Sensor Network: Initial results, Radio Sci., 47, RS0L17, doi:10.1029/2011RS004978, 2012. 
Yizengaw, E. and Moldwin, M. B.: African Meridian B-field Education and Research (AMBER) Array, Earth Moon Planet, 104, 237-246, doi:10.1007/s11038-008-9287-2, 2009.

Yizengaw, E., Moldwin, M. B., Mebrahtu, A., Damtie, B., Zesta, E., Valladares, C. E., and Doherty, P. H.: Comparison of storm time equatorial ionospheric electrodynamics in the African and American sectors, J. Atmos. Solar-Terr. Phys., 73, 156-163, 2011.

Yizengaw, E., Zesta, E., Moldwin, M. B., Damtie, B., Mebrahtu, A., Valladares, C. E., and Pfaff, R. F.: Longitudinal differences of ionospheric vertical density distribution and equatorial electrodynamics, J. Geophys. Res., 117, A07312, doi:10.1029/2011JA017454, 2012.
Yizengaw, E., Doherty, P., and Fuller-Rowell, T.: Is Space Weather Different Over Africa, and If So, Why? AGU Chapman Conference Report, Space Weather, 389-391, doi:10.1002/swe.20063, 2013a.

Yizengaw, E., Retterer, J., Pacheco, E. E., Roddy, P., Groves, K., Caton, R., and Baki, P.: Post-midnight Bubbles and Scintillations in the Quiet-Time June Solstice, Geophys. Res. Lett., 40, 55925597, doi:10.1002/2013GL058307, 2013b. 